\section{Controversias respecto al uso de estatinas en el síndrome coronario agudo}

\section{Controversies regarding the use of statins in the acute coronary syndrome}

\section{Estimado Editor:}

He leído el artículo de Ruiz Bailen ${ }^{1}$, respecto a las estatinas en la fase aguda del síndrome coronario agudo, y coincido respecto a que falta evidencia clara que respalde su uso. Sin embargo, a pesar de lo que expresa el autor, no podríamos sugerirlos como terapéutica habitual para pacientes con el síndrome hasta que no se diluciden algunas de las hipótesis sobre los mecanismos de acción y efectos pleiotrópicos de las estatinas.

El eje de algunos de los efectos pleiotrópicos de las estatinas es la disminución del mevalonato que es el precursor del colesterol y de compuestos isoprenoides no esteroideos, al lograr la inhibición de la HMG-CoA reductasa ${ }^{2}$.

Tales efectos incluyen varios que resultan beneficiosos y cardioprotectivos, como mejoría en la función endotelial, incremento de la biodisponibilidad de óxido nítrico, y otros como una actividad inmunosupresora paulatina, capacidad de reclutar células progenitoras endoteliales e inhibición de la hipertrofia ventricular ${ }^{3}$.

Sin embargo, al inhibir la síntesis de ácido mevalónico desciende la producción de ubiquinona (o coenzima Q10) que se encuentra en cantidades importantes en el corazón y es un componente esencial de la cadena respiratoria mitocondrial. Las estatinas, al interferir en la síntesis de ubiquinona afectan la función mitocondrial y producen un efecto deletéreo sobre el músculo cardiaco, al disminuir la producción de ATP y desacoplar la fosforilación oxidativa produciendo radicales libres ${ }^{4}$.

Otro efecto no benéfico de las estatinas es la disminución de la selenocisteína-tRNA, que controla la expresión de todas las selenoproteínas. Al ser interrumpida la vía del mevalonato, la selenoproteína-tRNA no puede transformarse en una molécula funcional. Tanto la disminución de la ubiquinona como la de selenoproteínas, estarían vinculadas a la miopatía por estatinas ${ }^{5}$.

Por ello, y a pesar que muchos pacientes con patología coronaria que ingresan a nuestras unidades de cuidados intensivos ya tienen una terapéutica usual con estatinas, debemos ser cautos al prescribir o indicar estos fármacos en pacientes con síndrome coronario agudo, y monitorizar aquellos que ya los consumen. Se debe sugerir fuertemente la realización de ensayos clínicos sobre la incorporación de estatinas en el arsenal terapéutico de un paciente con síndrome coronario agudo, y también se deben apoyar las investigaciones experimentales que nos permitan conocer los aspectos aún no aclarados de estos fármacos.

\section{Bibliografía}

1. Ruiz-Ballen M. Administración de estatinas durante la fase aguda del síndrome coronario agudo. Med Intensiva. 2010;34:56-63.

2. Istvan ES, Deisenhofer J. Structural mechanism for statin inhibition of HMG-CoA reductasa. Science. 2001;292:1160-4.

3. Davignon J. The cardioprotective effects of statins. Curr Atheroscler Rep. 2004;6:27-35.

4. Mortensen SA, Leth A, Agner E, Rohde M. Dose-related decrease of serum coenzyme Q10 during treatment with HMG-CoA reductase inhibitors. Mol Aspects Med. 1997;18:S137-44.

5. Moosmann B, Behl C. Selenoprotein synthesis and dide-effects of statins. Lancet. 2004;363:892-4.

\section{Camps ${ }^{\mathrm{a}, \mathrm{b}}$}

${ }^{a}$ Facultad de Medicina, Universidad Católica de Córdoba, Argentina

bUnidad de Terapia Intensiva, Clínica Privada Modelo

de Río Tercero, Córdoba, Argentina

Correo electrónico: editorfm@gmail.com

\section{Administración precoz de estatinas sobre el síndrome coronario agudo}

\section{Early administration of statins in acute coronary syndrome}

\section{Sr. Editor:}

En respuesta a la carta del Dr. Camps sobre el «uso precoz de las estatinas en el síndrome coronario agudo (SCA)», coincido, y así lo expongo en el texto original ${ }^{1}$, en la existencia de controversia en la administración precoz de estatinas, pues existen muchos estudios con gran heterogeneidad, aunque la lectura de estos muestra que la mayoría de ellos coincide en encontrar efectos beneficiosos en la administración de estatinas sobre el SCA, beneficio que se podría traducir en una disminución de la mortalidad precoz.
Molyneux ha demostrado en un reciente estudio que el nivel elevado de coenzima Q10 se asocia con una disminución de la mortalidad ante la insuficiencia cardiaca crónica ${ }^{2}$. Las estatinas disminuyen esta coenzima Q10, pero también disminuyen claramente la mortalidad en la enfermedad cardiovascular, lo que podría ser paradójico. No obstante, debemos recordar que esta coenzima Q10 es «una más» de las múltiples vías que se modifican, con la administración de estatinas, en la vía del colesterol. A pesar de que uno de los múltiples efectos deletéreos de las estatinas sean los mencionados por el Dr. Camps, también se conocen múltiples mecanismos bioquímicos por inhibición de «metabolitos intermedios», que claramente tienen efectos deletéreos al alterar el sistema inflamatorio, procoagulante, o la neovascularización, entre otros ${ }^{1}$. En cualquier caso, el resultado medible final es la supervivencia, y este objetivo final parece que es mejor con la administración de estatinas.

Esta carta podría hacer una pregunta aun más interesante: ¿qué tiene más valor, una decisión basada en fisiopatología o una evidencia? Obviamente, ante una débil evidencia 